
\title{
25 Research Soure \\ Current Obesity Was Associated with Hypertension in Children Born Very Low Birth Weight
}

Chompoonut Limratchapong

: Mahidol University Faculty of Medicine Ramathibodi Hospital

\section{Pracha Nuntnarumit}

: Mahidol University Faculty of Medicine Ramathibodi Hospital

\section{Wischuri Paksi}

: Mahidol University Faculty of Medicine Ramathibodi Hospital

Kwanchai Pirojsakul ( $\triangle$ Kwanchai.pio@mahidol.ac.th )

Mahidol University Faculty of Medicine Ramathibodi Hospital https://orcid.org/0000-0002-9043-6689

\section{Research note}

Keywords: masked hypertension, preterm, very low birth weight, ambulatory blood pressure monitoring, obesity

Posted Date: March 18th, 2021

DOI: https://doi.org/10.21203/rs.3.rs-322269/v1

License: (1) (1) This work is licensed under a Creative Commons Attribution 4.0 International License. Read Full License 


\section{Abstract}

Objectives: Previous studies from the developed countries showed that children born very low birth weight have a higher risk of hypertension compared with that of the normal birth weight controls. However, studies regarding the prevalence of hypertension in such children from the developing countries are scarce. This study aimed to identify the perinatal and postnatal factors associated with hypertension in children born very low birth weight.

Results: Forty-six children aged $\geq 6$ years from the VLBW cohort of Ramathibodi Hospital, Bangkok, Thailand underwent the ambulatory blood pressure monitoring. The prevalence of hypertension was $15.2 \%(7 / 46)$. The hypertension group had a significant higher BMI z-score at 3 years of age $(0.90 \pm 1.44$ vs $-0.45 \pm 1.47, P=0.045)$ and a greater proportion of current obesity ( $42 \%$ vs $2.5 \%, P<0.01)$ compared to those in the normotensive group. Multivariate analysis revealed that current obesity was associated with hypertension (OR 20.5, 95\% Cl 1.07-391.5). Among 36 children with normal office blood pressure, four children (11.1\%) had high blood pressure uncovered by ABPM, so-called "masked hypertension". Office systolic blood pressure at the 85th percentile was the greatest predictor for masked hypertension with a sensitivity of $75 \%$ and a specificity of $81.2 \%$.

\section{Introduction}

The World Health Organization estimated the prevalence of preterm birth to be 5-18\% across 184 countries and the preterm birth rates have been increasing in almost all countries ${ }^{1}$. Advances in perinatal medicine have led to a continuous decrease in the mortality of these children ${ }^{2}$. In preterm survivors, there is a high rate of long-term complications such as recurrent hospitalizations, long-term neurodevelopmental impairment, and chronic health problems, including hypertension and vascular change. Previous studies have shown that preterm with low birth weight is a risk factor for higher office blood pressure compared with that of the term and normal birth weight controls ${ }^{3-6}$.

Patients who have normal office blood pressure but elevated out-of-office blood pressure are called having "masked hypertension" 7 . Compared to normotensive children, children with masked hypertension have a significant risk for end-organ damage ${ }^{8-10}$. Ambulatory blood pressure monitoring (ABPM) can uncover masked hypertension in children with normal office blood pressure, detect white coat hypertension and confirm hypertension in children with elevated office blood pressure. Among children and adolescents, the estimated prevalence of masked hypertension ranged from 7.4-11.0\% 11,12 . Previous studies have shown that children born very low birth weight (VLBW) had higher both awake and sleep BP with reduced nocturnal dipping compared with those of the normal birthweight individuals $4,13-$ 15. This study was aimed to assess office and ambulatory blood pressure in children born VLBW and to identify perinatal, postnatal and present clinical parameters associated with hypertension. In addition, we aimed to identify the parameter for the prediction of masked hypertension in children who had normal office blood pressure. 


\section{Methods}

Children aged $\geq 6$ years from the cohort of children born VLBW ( $<1500$ grams) at Ramathibodi Hospital, Bangkok, Thailand were enrolled. Children who had chronic diseases that may contribute to the development of hypertension e.g. known kidney diseases, etc., or who were not contactable at the time of recruitment were excluded. Detailed perinatal data were collected including gestational age, birth weight, maternal hypertension during pregnancy, antenatal steroid therapy, umbilical catheter insertion, and other perinatal problems such as respiratory distress syndrome, bronchopulmonary dysplasia, intraventricular hemorrhage, etc. The birth weight z-score was calculated according to the Fenton growth for preterm infants. ${ }^{16,17}$ Being small for gestational age was defined as a z-score less than -2 for sex and gestational age. Patients from the VLBW cohort had been assessed postnatal weight and height since birth to at least 3 years of age, their ages were analyzed with correction for prematurity. The data at time of enrollment were collected including demographic data (sex, age); anthropometric data (weight, height, body mass index (BMI), waist circumference); laboratory values (serum creatinine, estimated glomerular filtration rate (eGFR) estimated by the bedside Schwartz formula ${ }^{18}$ and urinalysis). Weight, height, and BMI were normalized to z-score using age- and sex-specific formulas provided by the Centers of Disease Control and Prevention ${ }^{19}$. Obesity is defined as a BMI $z$-score $\geq 2$. Waist circumference-height ratio was calculated using waist circumference $(\mathrm{cm}) /$ height $(\mathrm{cm})$.

Measurements of office blood pressure were performed by oscillometric method using Dinamap ${ }^{\mathrm{TM}} \mathrm{V} 100$ (GE Healthcare, Chicago, Illinois, USA). The device was applied in the right arm with a corrected cuff size. Readings were taken three times after resting for five minutes between measurements and the average of the three measurements was used for analysis. Z-scores of office blood pressure were calculated based on the normative pediatric BP tables of normal-weight children by the American Academy of Pediatrics ${ }^{7}$. Office hypertension was defined as systolic blood pressure (SBP) and/or diastolic blood pressure (DBP) $z$-score $\geq 95$ th percentile adjusted for sex, age, and height.

ABPM was performed with the A\&D TM-2430 device (A\&D, Tokyo, Japan), which has been validated for use in children and adolescents ${ }^{20}$. Measurements were performed every 20 minutes during awake and every 30 minutes during sleep. Patients were instructed to perform their routine activities, avoid vigorous activities and to record their daily activities and time they woke up and went to sleep. ABPM was considered adequate if there were $\geq 40$ valid BP readings for the entire 24 -hour period. Sustained hypertension is defined as having a high office blood pressure and mean ambulatory SBP or DBP $\geq$ the 95th percentile for gender and height and blood pressure load $\geq 25 \%$ either awake, sleep or both periods according to the current guidelines. ${ }^{21}$ Masked hypertension is defined as having a normal office BP but high ambulatory blood pressure as defined previously. Whitecoat hypertension is defined as having a high office blood pressure but normal ambulatory blood pressure.

The IBM SPSS $\AA$ software version 22 was used for analysis. Data were presented as percentages, mean and standard deviation or median and interquartile range (IQR), as appropriate. Categorical data were compared using the chi-square test or Fisher's exact test, as appropriate. Student's t-test or Mann-Whitney 
U test was used for comparison of continuous data between the two groups, as appropriate. Bivariate logistic regression analysis was used to identify the factors associated with hypertension. The receiver operating characteristic (ROC) curve was used to analyze the performance of the parameters for detecting masked hypertension. A $p$-value $<0.05$ was considered statistically significant.

\section{Results}

The data of all patients born VLBW in the pediatric department during the years 2004 and 2012 were reviewed. From this population (402 patients), only 110 patients were contactable at the time of recruitment due to changes in the address and telephone numbers. Of these, 37 patients were living in the other regions and 10 patients refused to participate in this study. Seventeen patients were excluded from the study due to severe BPD (1), obstructive sleep apnea (4), known chronic kidney diseases (3), central nervous system anomalies (2), and attention deficit hyperactivity disorder who received psychostimulants (7). Therefore, 46 patients (19 males) participated in this study. Baseline characteristics of all participants were summarized in Table 1. 
Table 1

Perinatal conditions and postnatal growth between patients with and without hypertension

\section{Parameters}

All patients Hypertension

$(\mathrm{N}=46)$

$(\mathrm{N}=7)$
No hypertension

$(\mathrm{N}=39)$

\section{Perinatal conditions}

\begin{tabular}{lllll} 
SGA, n (\%) & $10(21)$ & $1(14)$ & $9(23)$ & 0.604 \\
\hline Mode of delivery, C/S, n (\%) & $31(67)$ & $3(42)$ & $28(71)$ & 0.193 \\
\hline GA (weeks), mean \pm SD & $29.70 \pm$ & $30.14 \pm 2.41$ & $29.62 \pm 2.97$ & 0.661 \\
\hline Birth weight (grams), mean \pm SD & $1,143 \pm 278$ & $1,237 \pm 227$ & $1,127 \pm 286$ & 0.341 \\
\hline Maternal preeclampsia, n (\%) & $15(33)$ & $2(28)$ & $13(33)$ & 0.807 \\
\hline Antenatal steroid used, n (\%) & $36(78)$ & $4(57)$ & $32(82)$ & 0.146 \\
\hline RDS, n (\%) & $26(56)$ & $4(57)$ & $22(56)$ & 0.971 \\
\hline TTNB, n (\%) & $7(15)$ & $1(14)$ & $6(15)$ & 0.941 \\
\hline BPD, n (\%) & $20(43)$ & $3(42)$ & $17(43)$ & 0.971 \\
\hline PDA, n (\%) & $18(39)$ & $2(28)$ & $16(41)$ & 0.534 \\
IVH, n (\%) & $10(22)$ & $2(28)$ & $8(20)$ & 0.634 \\
NEC, n (\%) & $5(11)$ & $0(0)$ & $5(12)$ & 0.316 \\
\hline Sepsis, n (\%) & $11(24)$ & $1(14)$ & $10(25)$ & 0.517 \\
\hline Aminoglycoside used, n (\%) & $34(74)$ & $6(85)$ & $28(71)$ & 0.589 \\
\hline TPN transfusion, n (\%) & $36(78)$ & $5(71)$ & $31(79)$ & 0.752 \\
\hline Invasive ventilator used, n (\%) & $17(37)$ & $1(14)$ & $16(41)$ & 0.177 \\
\hline UAC insertion, n (\%) & $28(61)$ & $4(57)$ & $24(61)$ & 0.809 \\
\hline UVC insertion, n (\%) & $32(70)$ & $4(57)$ & $28(71)$ & 0.796 \\
\hline Length of stay (days), mean \pm SD & $59 \pm 29$ & $54 \pm 28$ & $60 \pm 29$ & 0.600 \\
\hline Discharge weight (grams), mean \pm SD & $2,619 \pm 634$ & $2,662 \pm 830$ & $2,612 \pm 606$ & 0.851 \\
\hline Pan & & & & \\
\hline
\end{tabular}

\section{Postnatal growth}

BPD, bronchopulmonary dysplasia; C/S, cesarean section; GA, gestational age; IVH, intraventricular hemorrhage; NEC, necrotizing enterocolitis; PDA, patent ductus arteriosus; RDS, respiratory distress syndrome; SD, standard deviation; SGA, small for gestational age; TPN, total parenteral nutrition; TTNB, transient tachypnea of the newborn; UAC, umbilical artery catheter; UVC, umbilical venous catheter 


\begin{tabular}{|lllll|}
\hline Parameters & $\begin{array}{l}\text { All patients } \\
\mathbf{N}=\mathbf{4 6})\end{array}$ & $\begin{array}{l}\text { Hypertension } \\
\mathbf{( N = 7 )}\end{array}$ & $\begin{array}{l}\text { No } \\
\text { hypertension } \\
\mathbf{( N = 3 9 )}\end{array}$ & P-value \\
\hline BMI z-score at 2 years old, mean \pm SD & $-0.37 \pm 1.20$ & $0.38 \pm 0.97$ & $-0.52 \pm 1.19$ & 0.090 \\
\hline $\begin{array}{l}\text { BMI z-score at 2.5 years old, mean } \pm \\
\text { SD }\end{array}$ & $-0.45 \pm 1.27$ & $0.36 \pm 1.07$ & $-0.58 \pm 1.26$ & 0.126 \\
\hline BMI z-score at 3 years old, mean \pm SD & $-0.24 \pm 1.54$ & $0.90 \pm 1.44$ & $-0.45 \pm 1.47$ & $\mathbf{0 . 0 4 5}$ \\
\hline $\begin{array}{l}\text { BPD, bronchopulmonary dysplasia; C/S, cesarean section; GA, gestational age; IVH, intraventricular } \\
\text { hemorrhage; NEC, necrotizing enterocolitis; PDA, patent ductus arteriosus; RDS, respiratory distress } \\
\text { syndrome; SD, standard deviation; SGA, small for gestational age; TPN, total parenteral nutrition; }\end{array}$ \\
$\begin{array}{l}\text { TTNB, transient tachypnea of the newborn; UAC, umbilical artery catheter; UVC, umbilical venous } \\
\text { catheter }\end{array}$ \\
\hline
\end{tabular}

Office blood pressure and ABPM were performed in all participants. Regarding office blood pressure, 10 patients of 46 participants (21.7\%) had office hypertension. Among patients with office hypertension, 3 patients had hypertension confirmed by ABPM so-called "sustained hypertension", while another 7 patients had normal ambulatory blood pressure so-called "white-coat hypertension". Regarding 36 patients with normal office blood pressure, 4 children (11.1\%) had masked hypertension uncovered by ABPM. Therefore, the overall prevalence of hypertension was $15.2 \%(7 / 46)$.

Comparisons of perinatal parameters and postnatal growth between patients with and without hypertension were presented in Table 1. The postnatal growth data showed that the group of patients with hypertension had a significantly higher mean BMI z-score at 3 years old compared to that of the normotensive group $(0.90 \pm 1.44$ vs $-0.45 \pm 1.47, P=0.045)$. Comparisons of the current anthropometric parameters and laboratory investigation between the groups with and without hypertension were presented in Table 2. The hypertensive group had a significant greater proportion of obesity ( $42 \%$ vs $2.5 \%$, $P<0.01)$ and higher WHR $(0.51 \pm 0.06$ vs $0.46 \pm 0.05, P=0.023)$ compared to those in the normotensive group. Multivariate analysis adjusted for birth weight and antenatal steroid exposure and birth weight showed that current obesity was a significant factor associated with hypertension (OR 20.45, $P=0.045$, $95 \% \mathrm{Cl} 1.07-391.5)$ as shown in Table 3. 
Table 2

Current demographic data, anthropometric data and laboratory investigation between hypertensive and normal groups

\begin{tabular}{|c|c|c|c|}
\hline Parameters & $\begin{array}{l}\text { Hypertension } \\
(\mathrm{N}=7)\end{array}$ & $\begin{array}{l}\text { No hypertension } \\
(\mathrm{N}=39)\end{array}$ & $P$-value \\
\hline \multicolumn{4}{|l|}{ Current demographic data } \\
\hline Gender, male, n (\%) & $3(42)$ & $16(41)$ & 0.611 \\
\hline Age (years) mean \pm SD & $8.57 \pm 2.14$ & $9.10 \pm 2.58$ & 0.928 \\
\hline \multicolumn{4}{|l|}{ Current anthropometric data } \\
\hline Body weight $(\mathrm{kg})$, mean \pm SD & $34.55 \pm 9.14$ & $32.39 \pm 13.14$ & 0.680 \\
\hline Body weight z-score, mean \pm SD & $0.79 \pm 1.84$ & $0.03 \pm 1.55$ & 0.256 \\
\hline Height $(\mathrm{cm})$, mean \pm SD & $133.24 \pm 7.14$ & $134.38 \pm 16.65$ & 0.860 \\
\hline Height z-score, mean \pm SD & $0.47 \pm 1.31$ & $0.09 \pm 1.25$ & 0.469 \\
\hline BMI z-score, mean \pm SD & $0.70 \pm 1.75$ & $-0.24 \pm 1.77$ & 0.200 \\
\hline Obesity, n (\%) & $3(42)$ & $1(2.5)$ & $<0.01$ \\
\hline Waist-height ratio $(\mathrm{cm} / \mathrm{cm})$, mean \pm SD & $0.51 \pm 0.06$ & $0.46 \pm 0.05$ & 0.023 \\
\hline \multicolumn{4}{|l|}{ Laboratory investigation } \\
\hline Serum creatinine $(\mathrm{mg} / \mathrm{dL})$, mean $\pm \mathrm{SD}$ & $0.47 \pm 0.07$ & $0.53 \pm 0.11$ & 0.211 \\
\hline $\mathrm{eGFR}\left(\mathrm{mL} / \mathrm{min} / 1.73 \mathrm{~m}^{2}\right)$, mean $\pm \mathrm{SD}$ & $117 \pm 16.42$ & $107 \pm 22.84$ & 0.316 \\
\hline Urinary protein positivity, n (\%) & $0(0)$ & $1(2.56)$ & 0.692 \\
\hline
\end{tabular}


Table 3

Association of perinatal and postnatal conditions and childhood hypertension

\begin{tabular}{|lllllll|}
\hline Parameters & \multicolumn{3}{l}{ Univariate analysis } & \multicolumn{3}{l|}{ Multivariate analysis } \\
\cline { 2 - 6 } & Exp $(\boldsymbol{\beta})$ & P-value & $\mathbf{9 5 \%} \mathrm{Cl}$ & Exp ( $\beta)$ & P-value & $\mathbf{9 5 \%} \mathrm{Cl}$ \\
\hline Current BMl z-score $\geq 2$ & 28.5 & $\mathbf{0 . 0 0 8}$ & $2.37-342.59$ & 20.45 & $\mathbf{0 . 0 4 5}$ & $1.07-391.50$ \\
\hline Antenatal steroid exposure & 0.37 & 0.337 & $0.05-2.77$ & 0.71 & 0.795 & $0.055-9.18$ \\
\hline Birth weight & 1.00 & 0.339 & $0.99-1.00$ & 1.00 & 0.617 & $0.99-1.00$ \\
\hline Sex, male & 1.07 & 0.928 & $0.21-5.48$ & & & \\
\hline Maternal preeclampsia & 1.02 & 0.979 & $0.15-7.00$ & & & \\
\hline BMI, body mass index & & & & & & \\
\hline
\end{tabular}

Regarding 36 children with normal office blood pressure, 4 patients with masked hypertension had a significantly higher mean office SBP $z$-score than that of the group without masked hypertension (1.10 \pm 0.35 vs $0.32 \pm 0.73, P=0.01)$. The ROC analysis showed that SBP $z$-score was the best predictor of masked hypertension with the area under the curve of 0.85 . The office SBP cutoff level at the 85th percentile had a sensitivity of $75 \%$ and a specificity of $81.2 \%$.

\section{Discussion}

The present study revealed that the overall prevalence of hypertension was $15.2 \%$ and the current obesity was the factor associated with hypertension. Moreover, office SBP above the 85th percentile was a good office BP parameter for the prediction of masked hypertension in children born VLBW who had normal office blood pressure.

The overall prevalence of hypertension in this cohort was higher than that of the previous reports of hypertension in children born preterm and VLBW, ranging from $6-13 \% 5,6,22$. This discordant finding could be explained by the fact that the present study used ABPM that can detect masked hypertension, while the previous studies used only the office blood pressure measurements. On the other hand, the prevalence of masked hypertension in this study was $8.6 \%$, similar to that reported globally, which estimated as $9-16 \%$ among the pediatric population $11,12,23-25$. Not only sustained hypertension but also masked hypertension is associated with the increase in carotid intimal media thickness and adverse cardiovascular structure in children and adolescents. ${ }^{8,10,26}$ This finding supports the current clinical practice guidelines that suggest using ABPM for hypertension screening in patients born prematurity and low birth weight. ${ }^{7}$

Our study demonstrated an association between current obesity and hypertension in children born VLBW which was consistent with the previous studies. The study from the USA found that obesity was 
significantly associated with hypertension and the rate of weight gain since birth among extremely LBW infants were associated with an increase in SBP. ${ }^{22}$ Lurbe $E$ et al. reported that all of the office, 24-hour, daytime and nighttime SBP were significantly higher in LBW Spanish children who became later obese. ${ }^{27}$ In addition, the present study found that the BMI z-score at 3 years of age was significantly higher in the group with hypertension than that of the group without hypertension. Lule SA et al. reported that the accelerated weight gain from birth to 6 months of age was associated with hypertension in the 2nd decade of life in LBW patients. ${ }^{28}$ These findings support that accelerated postnatal growth is associated with childhood hypertension. The other studies also reported maternal preeclampsia and antenatal steroid as the additional risk factors for hypertension. ${ }^{5,6}$ However, this study showed no association between these factors and hypertension. This might be the result of a small number of participants in the present study.

The present study identified that the cutoff level of office SBP at the 85th percentile had the highest sensitivity (75\%) and specificity (81.2\%) to predict masked hypertension. Hamdani G et al. reported that the 85th percentile of SBP had a sensitivity of $86.8 \%$ and a specificity of $57.4 \%$ to diagnose ambulatory hypertension in healthy adolescents. ${ }^{29}$ As same as the study of Centra JC et al, office SBP measurement of $\geq 122.5 \mathrm{mmHg}$ that was equal to the 85th percentile of SBP predicted masked hypertension in adults born extreme preterm and extremely LBW with a sensitivity and a specificity of $79 \%$ and $74 \%$, respectively. ${ }^{3}$ Interestingly, our study found that the prevalence of white-coat hypertension was relatively high at 70\% (7/10) and it was higher than previous reports in previously healthy children and adolescents, which estimated $34-58 \% .{ }^{10}, 11,30,31$ Therefore, using ABPM to exclude white-coat hypertension also might be useful in children born VLBW, which could prevent unnecessary investigation and use of antihypertensive medication.

\section{Conclusion}

The prevalence of hypertension was $15.2 \%$ in this cohort of children born VLBW. The current obesity was an independent factor associated with hypertension during the childhood period.

\section{Limitations}

The present study had some limitations. The sample size was small, especially the proportion of children with masked hypertension. This might not have enough power to detect some differences of the parameters between the groups with and without hypertension. Due to a retrospective design with a cross-sectional survey, incomplete data existed. Lastly, there was no available standard ambulatory blood pressure tables for Thai children, so the authors used a normogram reported by the European investigators. $^{32}$

\section{List Of Abbreviations}


ABPM, ambulatory blood pressure monitoring; VLBW, very low birth weight; BPD, bronchopulmonary dysplasia; C/S, cesarean section; GA, gestational age; IVH, intraventricular hemorrhage; NEC, necrotizing enterocolitis; PDA, patent ductus arteriosus; RDS, respiratory distress syndrome; SD, standard deviation; SGA, small for gestational age; TPN, total parenteral nutrition; TTNB, transient tachypnea of the newborn; UAC, umbilical artery catheter; UVC, umbilical venous catheter; BMI, body mass index; eGFR, estimate glomerular filtration rate; SD, standard deviation

\section{Declarations}

\section{Ethics approval and consent to participate}

This study was approved by the Ramathibodi Hospital Ethics Committee for Human Research (MURA $2016 / 776$ ). Written consent from a legal guardian and assent from participating children aged $\geq 7$ years were obtained.

\section{Consent for publication}

Not applicable.

\section{Availability of data and materials}

Data will be obtained up on a reasonable request by emailing to the corresponding author using “kwanchai.pio@mahidol.ac.th”.

\section{Competing interests}

All the authors declare no competing interests regarding this work.

\section{Funding}

This study received the funding from the Ramathibodi Hospital Research Grant.

\section{Authors' contributions}

C.L., P.N., W.P. and K.P. designed the study. C.L., W.P. and K.P. performed the research. C.L. and K.P. analyzed the data. C.L. and K.P. wrote the paper. C.L., P.N, W.P. and K.P. read and approved the final manuscript.

\section{Acknowledgments}

The authors are grateful to the participated patients and families. We are thankful for Ms. Witchuri Paksi, R.N. for the preparation of ABPM, Ms. Archara Tangnoo, a neonatal intensive care nurse for the providence of peri-natal data, and Ms. Umaporn Udomsubpayakul, for statistical analysis. We also would like to thank Mr. Wirot Phairotsakun, Mrs. Kittirat Phairotsakun, Mr. Khobchai Phairotsakun and Mr. Naratach Chayakul for donating the TM-2430 devices. 


\section{References}

1. World Health O. Born too soon: the global action report on preterm birth. Geneva: World Health Organization; 2012.

2. Poplawska K, Dudek K, Koziarz M, Cieniawski D, Drożdż T, Smiałek S, Drożdż D, Kwinta P. Prematurity-related hypertension in children and adolescents. Int J Pediatr 2012 2012:537936.

3. Centra JC, Roberts G, Opie G, Cheong J, Doyle LW. Masked hypertension in extremely preterm adolescents. J Paediatr Child Health 2015 51:1060-5.

4. Doyle LW, Faber B, Callanan C, Morley R. Blood pressure in late adolescence and very low birth weight. Pediatrics 2003 111:252-7.

5. Hovi P, Vohr B, Ment LR, Doyle LW, McGarvey L, Morrison KM, Evensen KA, van der Pal S, Grunau RE, Brubakk AM, Andersson S, Saigal S, Kajantie E. Blood Pressure in Young Adults Born at Very Low Birth Weight: Adults Born Preterm International Collaboration. Hypertension 2016 68:880-7.

6. Vieux R, Gerard M, Roussel A, Sow A, Gatin A, Guillemin F, Hascoet JM. Kidneys in 5-year-old pretermborn children: a longitudinal cohort monitoring of renal function. Pediatr Res 2017 82:979-85.

7. Flynn JT, Kaelber DC, Baker-Smith CM, Blowey D, Carroll AE, Daniels SR, de Ferranti SD, Dionne JM, Falkner B, Flinn SK, Gidding SS, Goodwin C, Leu MG, Powers ME, Rea C, Samuels J, Simasek M, Thaker VV, Urbina EM, Subcommittee On S, Management Of High Blood Pressure In C. Clinical Practice Guideline for Screening and Management of High Blood Pressure in Children and Adolescents. Pediatrics 2017 140: pii: e20171904. doi: 10.1542/peds.2017-1904.

8. McNiece KL, Gupta-Malhotra M, Samuels J, Bell C, Garcia K, Poffenbarger T, Sorof JM, Portman RJ. Left ventricular hypertrophy in hypertensive adolescents: analysis of risk by 2004 National High Blood Pressure Education Program Working Group staging criteria. Hypertension 2007 50:392-5.

9. Mitsnefes M, Flynn J, Cohn S, Samuels J, Blydt-Hansen T, Saland J, Kimball T, Furth S, Warady B. Masked hypertension associates with left ventricular hypertrophy in children with CKD. J Am Soc Nephrol 2010 21:137-44.

10. Stabouli S, Kotsis V, Toumanidis S, Papamichael C, Constantopoulos A, Zakopoulos N. White-coat and masked hypertension in children: association with target-organ damage. Pediatr Nephrol 2005 20:1151-5.

11. Lurbe E, Torro I, Alvarez V, Nawrot T, Paya R, Redon J, Staessen JA. Prevalence, persistence, and clinical significance of masked hypertension in youth. Hypertension 2005 45:493-8.

12. Matsuoka S, Awazu M. Masked hypertension in children and young adults. Pediatr Nephrol 2004 19:651-4.

13. Bayrakci US, Schaefer F, Duzova A, Yigit S, Bakkaloglu A. Abnormal circadian blood pressure regulation in children born preterm. J Pediatr 2007 151:399-403.

14. Salgado CM, Jardim PC, Teles FB, Nunes MC. Low birth weight as a marker of changes in ambulatory blood pressure monitoring. Arq Bras Cardiol 2009 92:107-21. 
15. Sipola-Leppanen M, Karvonen R, Tikanmaki M, Matinolli HM, Martikainen S, Pesonen AK, Raikkonen K, Jarvelin MR, Hovi P, Eriksson JG, Vaarasmaki M, Kajantie E. Ambulatory blood pressure and its variability in adults born preterm. Hypertension 2015 65:615-21.

16. Chou JH, Roumiantsev S, Singh R. PediTools Electronic Growth Chart Calculators: Applications in Clinical Care, Research, and Quality Improvement. J Med Internet Res 2020 22:e16204.

17. Fenton TR, Kim JH. A systematic review and meta-analysis to revise the Fenton growth chart for preterm infants. BMC Pediatr 2013 13:59.

18. Schwartz GJ, Munoz A, Schneider MF, Mak RH, Kaskel F, Warady BA, Furth SL. New equations to estimate GFR in children with CKD. J Am Soc Nephrol 2009 20:629-37.

19. Centers for Disease Control and Prevention. Table for calculated body mass index values for selected heights and weights for ages 2 to 20 [Available from: http://www.dishdiet.com/teen_kids_bmi_calculator.pdf.

20. Yip GW, So HK, Li AM, Tomlinson B, Wong SN, Sung RY. Validation of A\&D TM-2430 upper-arm blood pressure monitor for ambulatory blood pressure monitoring in children and adolescents, according to the British Hypertension Society protocol. Blood Press Monit 2012 17:76-9.

21. Flynn JT, Daniels SR, Hayman LL, Maahs DM, McCrindle BW, Mitsnefes M, Zachariah JP, Urbina EM. Update: ambulatory blood pressure monitoring in children and adolescents: a scientific statement from the American Heart Association. Hypertension 2014 63:1116-35.

22. Mhanna MJ, Iqbal AM, Kaelber DC. Weight gain and hypertension at three years of age and older in extremely low birth weight infants. J Neonatal Perinatal Med 2015 8:363-9.

23. Fujita H, Matsuoka S, Awazu M. Masked Isolated Nocturnal Hypertension in Children and Young Adults. Pediatr Cardiol 2018 39:66-70.

24. Iturzaeta A, Pompozzi L, Casas Rey C, Passarelli I, Torres F. Prevalence of masked hypertension among children with risk factors for arterial hypertension. Arch Argent Pediatr 2018 116:328-32.

25. Lurbe E, Cifkova R, Cruickshank JK, Dillon MJ, Ferreira I, Invitti C, Kuznetsova T, Laurent S, Mancia G, Morales-Olivas F, Rascher W, Redon J, Schaefer F, Seeman T, Stergiou G, Wuhl E, Zanchetti A. Management of high blood pressure in children and adolescents: recommendations of the European Society of Hypertension. J Hypertens 2009 27:1719-42.

26. Huang Z, Sharman JE, Fonseca R, Park C, Chaturvedi N, Davey Smith G, Howe LD, Lawlor DA, Hughes AD, Schultz MG. Masked hypertension and submaximal exercise blood pressure among adolescents from the Avon Longitudinal Study of Parents and Children (ALSPAC). Scand J Med Sci Sports 2020 30:25-30.

27. Lurbe E, Carvajal E, Torro I, Aguilar F, Alvarez J, Redon J. Influence of concurrent obesity and low birth weight on blood pressure phenotype in youth. Hypertension 2009 53:912-7.

28. Lule SA, Namara B, Akurut H, Muhangi L, Lubyayi L, Nampijja M, Akello F, Tumusiime J, Aujo JC, Oduru G, Smeeth L, Elliott AM, Webb EL. Are birthweight and postnatal weight gain in childhood associated with blood pressure in early adolescence? Results from a Ugandan birth cohort. Int J Epidemiol 2019 48:148-56.

Page $12 / 13$ 
29. Hamdani G, Flynn JT, Becker RC, Daniels SR, Falkner B, Hanevold CD, Ingelfinger JR, Lande MB, Martin LJ, Meyers KE, Mitsnefes M, Rosner B, Samuels JA, Urbina EM. Prediction of Ambulatory Hypertension Based on Clinic Blood Pressure Percentile in Adolescents. Hypertension 2018 72:95561.

30. Matsuoka S, Kawamura K, Honda M, Awazu M. White coat effect and white coat hypertension in pediatric patients. Pediatr Nephrol 2002 17:950-3.

31. Sorof JM, Portman RJ. White coat hypertension in children with elevated casual blood pressure. J Pediatr 2000 137:493-7.

32. Wuhl E, Witte K, Soergel M, Mehls O, Schaefer F. Distribution of 24-h ambulatory blood pressure in children: normalized reference values and role of body dimensions. J Hypertens 2002 20:1995-2007. 